\title{
Conditioned avoidance response perseveration in septal rats during massed extinction trials
}

\author{
T. J. La VAQUE \\ NEW MEXICO HIGHLANDS UNIVERSITY ${ }^{1}$
}

Ten septal rats were compared with 10 normal controls on the acquisition and massed extinction of a conditioned avoidance response (CAR) in a two-way shuttlebox. The two groups did not differ during the acquisition phase of the experiment, however, eight of the normal Ss reached extinction criterion within the first extinction session, whereas nine of the septal $S$ s did not extinguish within six extinction sessions.

The behavioral effects of septal lesions have been interpreted as resulting from loss of response inhibition (McCleary, 1961; Kaada, Rasmussen, \& Kveim, 1962; Schwartzbaum, Kellicutt, Spieth, \& Thompson, 1964). Septal lesions produce a deficit in passive avoidance (Kaada et al, 1962; McCleary, 1961), but appear to enhance the acquisition of a conditioned avoidance response (CAR) (Kenyon \& Krieckhaus, 1965; McCleary, 1961; Thomas \& Van Atta, 1966). Schwartzbaum et al (1964) reported that septal damage resulted in increased perseverative error in a brightness discrimination task, and prolonged the extinction of an operant response to a preoperatively acquired tone discrimination. In addition, Zucker \& McCleary (1964) found that septal cats made more perseverative errors when required to reverse a learned position habit. The same study reported that septal lesions resulted in the prolonged extinction of a CAR when the Ss generalized to a novel $\mathrm{CS}$, and were punished for responding, but the prolonged extinction did not occur when the Ss were extinguished to the training CS without punishment for responding. Zucker (1965) obtained comparable punished extinction results.

The position reversal data, passive avoidance data, and operant data suggest that the phenomenon of response perseveration is a general characteristic of septal Ss. If damage to the septum does result in the loss of response inhibition, the effect should be seen in the prolonged extinction of a CAR, whether the response during the extinction trials is punished or not.

The present study was designed to test for differential CAR extinction rates between septal and normal Ss. It was specifically hypothesized that Ss having sustained septal lesions would require more trials to reach extinction criterion than would the controls.

Method

The Ss were 20 male Sprague-Dawley albino rats that averaged $300 \mathrm{gm}$ in body weight at the beginning of the experiment. Ten of the Ss received bilateral lesions in the septal region. The coordinates were: $1 \mathrm{~mm}$ anterior to the bregma, $3 \mathrm{~mm}$ lateral, $25.5^{\circ}$ toward the midline, and $5.5 \mathrm{~mm}$ deep. A 2 ma current was applied for $20 \mathrm{sec}$. in each electrode placement. Histological verification was made of each lesion site. The septal group began CAR training after a three day postoperative recovery period. The other $10 \mathrm{Ss}$ served as unoperated controls.

The CS source in each compartment of the shuttlebox was from six 6-v a.c. light bulbs reduced to 4.6-v a.c., set three on each side of the compartment below the grid. The UCS was a .20 mad.c. shock supplied through the grid floor in the Ss compartment. The shuttlebox was programmed to follow the S's intertrial responses and thus present the CSand UCS in the appropriate compartment. Response latencies were recorded to the nearest .01 sec.

All Ss were given one 50 trial session per day. Each trial consisted of a $1 \mathrm{~min}$. intertrial interval and a 10 sec. CS-UCS interval. The CS continued with the UCS until S crossed the barrier, terminating both light and shock simultaneously. The learning criterion was set at $90 \%$ avoidance (45 out of any 50 trials) measured across or within sessions.

The extinction trials were massed with an $8 \mathrm{sec}$. intertrial interval separating $10 \mathrm{sec}$. CS-UCS periods. If $S$ failed to cross the barrier during the $10 \mathrm{sec}$. interval, the CS was terminated without presentation of the UCS. An avoidance response during the extinction phase of the experiment was the same as during acquisition, i.e., any response made to the opposite, unlit, chamber during the $10 \mathrm{sec}$. CS period with termination of the CS. The extinction criterion was set at $30 \%$ avoidance or below ( 15 out of 50 trials) across or within sessions. If any $S$ failed to reach the extinction criterion by 300 trials (six days) testing was discontinued for that $\mathrm{S}$. Results

The acquisition data indicate no significant difference between the groups in speed of acquisition of the CAR. The septal group required a mean of 99.3 trials compared to 101.8 trials for the control group to reach the learning criterion.

The extinction data were very clear cut, as shown in Fig. 1. Of the 10 normal Ss, eight reached the extinction criterion within the first session, one reached the extinction criterion at 73 trials, and one normal $\mathrm{S}$ did not reach the extinction criterion within the set limit of six sessions.

The septal group extinction data presents a radically different picture. Nine of the 10 septal Ss did not reach the extinction criterion within the six session limit, while the remaining $\mathrm{S}$ reached criterion at trial 184 , or mid- 


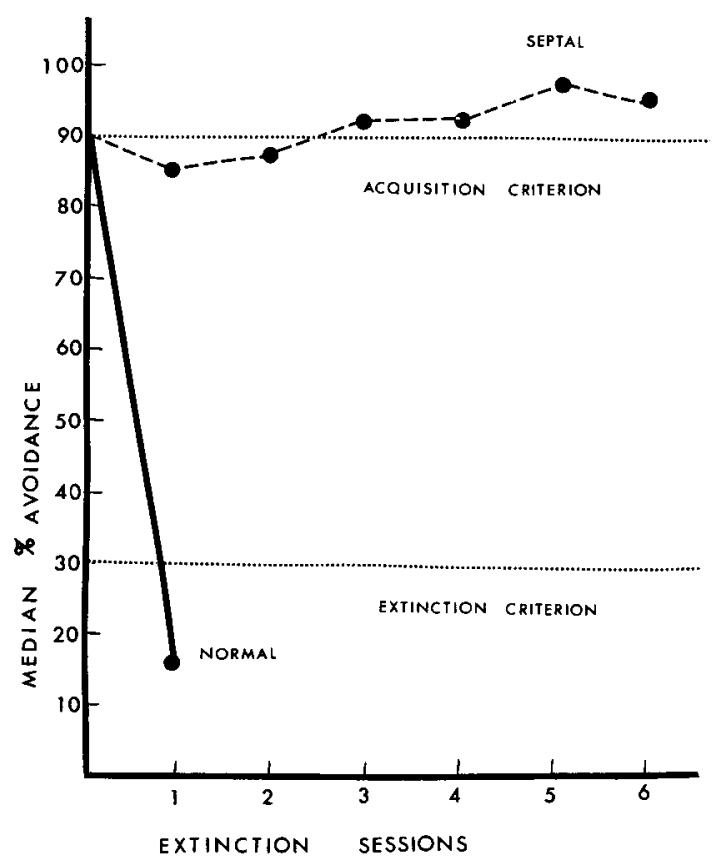

Fig. 1. Median percent avoidance per extinction session for normal and septal rats.

way through session four. Of equal interest is the fact that seven of the septal Ss apparently improved in avoidance performance during the extinction sessions.

The chi square test of significance between the groups for the number of Ss which extinguished within six sessions as opposed to those which did not is significant at the .001 level $\left(X^{2}=13.32, d f=1\right)$. The Mann-Whitney rank order analysis for the number of avoidance responses during the first extinction session indicates a difference between the groups at the .003 level of significance $(U=5)$.

\section{Discussion}

The results are consistent with the response inhibition hypothesis. They suggest that the effects of septal damage may be viewed as being a neurological release phenomenon which allows a more exaggerated expression of a response in the S's repertoire. The increase in the number of avoidance responses made during the later extinction sessions also suggests that the operated Ss may have been photosensitive, and that the CS became an aversive stimulus. The two hypotheses are not necessarily contradictory; it is known that light onset can be an aversive stimulus to rats (Lockard, 1963). Once the avoidance response had been established in the operated Ss of this experiment, the mere onset of light may have been sufficiently aversive to support the otherwise low-level light-escape response independently of the shock avoidance response.

The results of the present study are not consistent with the report of Zucker \& McCleary (1964) that the unpunished extinction of a CAR is not prolonged by septal lesions. Their data suggest that punishment for a response was the variable which prolonged extinction, but that variable was missing in the present experiment, and response perseveration occurred. It is difficult to assess what effect the massing of the extinction trials had in terms of the group differences during extinction. It would appear that massing resulted in very rapid extinction in the normal group, but not the septal group, and thus the differences between the groups was expanded. There is very little data to indicate the extent to which methodological variations affect septal response perseveration; however, it does appear to be a consistent phenomenon. Research is now in progress to explore the differential effects of intertrial intervals upon septal and normal Ss during CAR extinction.

\section{References}

Kaada, B. R., Rasmussen, E. W., \& Kveim, O. Impaired acquisition of passive avoidance behavior by subcallosal, septal, and hypothalamic lesions in rats. J. comp. physiol. Psychol., 1962, $55,661-670$.

Kenyon, J., \& Krieckhaus, E. E. Enhanced avoidance behavior following septal lesions in the rat as a function of lesion size and spontaneous activity. J. Comp. physiol. Psychol., 1965, $59,466-468$.

Lockard, R. B. Some effects of light upon the behavior of rodents. Psychol. Bull.., 1963, 60, 509-529.

McCleary, R. A. Response specificity in the behavioral effects of limbic system lesions in the cat. J. comp. physiol. Psychol., $1961,54,605-613$.

Schwartzbaum, J., Kellicut, M., Spieth, R., \& Thompson, J. The effects of septal lesions in rats on response inhibition associated with food reinforced behavior. J. comp. physiol. Psychol., $1964,58,217-224$.

Thomas, J. B., \& Van Atta, Loche. Hyperirritability and enhanced acquisition of the CAR as a function of lesion size in the rat following septal lesions. Paper read at the Midwestern Psychological Association, Chicago, May 6, 1966.

Zucker, I., \& McCleary, R. A. Perseveration in septal cats. Psychon. Sci., 1964, 1, 387-388.

Zucker, I. Effect of lesions of the septal-limbic area on the behavior of cats. J. comp. physiol. Psychol., 1965, 60, 344-352.

Note

1. Now at Kansas State University. 